
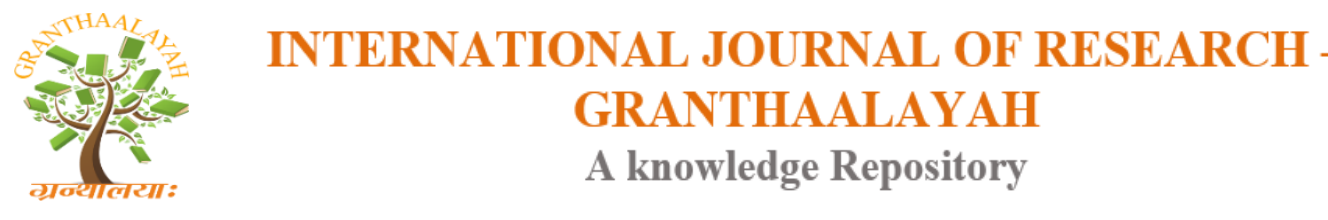

Social

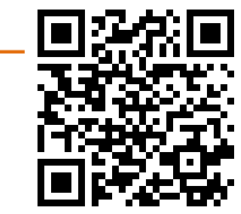

\title{
THE ELEMENTS THAT INFLUENCE THE PROFESSIONAL CONDUCT OF TEACHERS INVOLVED IN EARLY EDUCATION
}

\author{
Aikaterini Makrogiannaki ${ }^{1}$, Ionela Roxana I. Urea ${ }^{2}$ \\ ${ }^{1}$ University of Bucharest, Ph. D. Student, Doctoral School in Educational Sciences, 90 Panduri \\ Street, District 5 Bucharest, P.O. 050663, Romania \\ ${ }^{2}$ University of Bucharest, Special Education Department, 90 Panduri Street, District 5 \\ Bucharest, P.O. 050663, Romania
}

\begin{abstract}
Teachers that work with little children provide the first educational services and constantly have to pay attention to accomplish the educational goals that are suitable for these children. Therefore, they develop, according with their professional experience, a specific conduct which is reflected in all their actions.

Our research had the aim to identify the elements that have impact upon professional conduct of teachers involved in early education and are relevant for quality of the early education

The paper tries to reveal the elements the influence the conduct of teachers that are involved in early education of the children.

In our research we used the "Questionnaire for assessing teachers professional conduct" b) the "Questionnaire for assessing conditions of teachers quality services provided", non-directive interviews; statistical processing methods.

The results that came from the data allow us to see the factors that have high impact upon the teachers 'professional conduct and also the conditions of objectifying this professional conduct.

The conclusions are significant for developing proper counselling programs addressed to parents that have child enrolled in kindergartens and to teachers that provided educational services for preschool children.
\end{abstract}

Keywords: Teacher's Professional Conduct; Factors; Early Education; Professional Development.

Cite This Article: Aikaterini Makrogiannaki, and Ionela Roxana I. Urea. (2019). "THE ELEMENTS THAT INFLUENCE THE PROFESSIONAL CONDUCT OF TEACHERS INVOLVED IN EARLY EDUCATION." International Journal of Research - Granthaalayah, 7(4), 261-269. https://doi.org/10.29121/granthaalayah.v7.i4.2019.896.

\section{Introduction}

Today, the human behaviour and human conduct are probably, the most intense subjects that reached the attention of the experts from social field. The studies, researches were focus on 
structural aspect of human behaviour and/ or human conducts and in particular, on specific ways of subject' manifestations in relation with subjects' age, area of living, gender, etc.

Human behaviour is an observable phenomenon of all the actions that a person does. It involves physical, verbal actions and facial expression and body languages in a system unity and in a constant interdependency. It provides constant information regarding: the person 'status, his/ her level of cognitive achievements, his/her emotional competences, his/her level of social integration Some experts in the social sciences stipulated that any behaviour that is done by a human bean has certain premises and an internal, psychological mediation (Rady, 1990); others, like Duffy, have pointed that human behaviour: a) has two dimensions: one vector and one executive, the fundamental orientations being at the level of the self; b) has a particular purpose: keeping a direction and integrating the partial facts in a whole; c) it is related with the concept of "human conduct" . (Fugăretu-Urea, 2007)

Human conduct means activity or action in all forms that take place on internally - subjective and external - motor, through the unity of mental and behavioural actions. They are classified and hierarchized in elementary, intermediate, and superior; or also as primary, secondary and tertiary. There are a lot of experts that done studies that tried to revealed features of human conduct in relation with different types of activities. Other experts, like P. Janet, has considered communication and social collaboration as having a significant role in the emancipation process of human conduct. Based on that, the human conducts are shaped and become individual and social one (Radu, 1991) and can be notice in currently day activities.

The researches concerning the human conduct revealed that each occupation/ profession has his own sent of conducts which define and normalize the actions developed by individuals. The rules are established according with: activities, dynamic of relationships stated on vertical and horizontal, products or services

Assessing the human conduct that is specific for a profession, become more a more a complex activity and usually it is completed by reference to specific behavioural profiles. These profiles of the employees are now the starting points in bench management process and also in analysing the quality of the provided services.

Professional conduct is currently one of the most investigated topic by the experts in social sciences. It involved specific standard of behaviour (Șchiopu, 1995) and it is bounded by code of ethics, morals that can prevent professional conflict of interests (Michael, Stark., 2001). Each profession, in each country, has his own code of ethics and constantly the penalties associated with breaking the code' rules are update. Each organization, public body, has regulations that respect the professional code of rules. In spite of the fact that each country has it own professional code for each profession, we can notice a common frame for the codes (Payne, Landry, 2006) and we can say, that some of the codes became universal.(Martin, 2013, Weinberg, Campbell, 2014).

In education, the teachers, educators, pedagogues have specific code of professional conduct. This code is made based on the each: Children' rights, Human' right, National Education Law, National Regulations in Education and it is address to all teachers, educators, pedagogue, regardless of the type of the educational services that they provided. 
Being a teacher, is not an easy task. In spite of the highly demanded professional background, teachers have to face also constant demands coming from all the partners involved in educational process: pupils/students/, parents, local authorities, international quality standards in education field, etc. In this context, the teachers have to play multiple roles in order to form and develop personality' structures that are adaptable to the social environment.

In early education, teachers work side by side with child' parents, educational experts, counsellors in the best interest of the child for his/her suitable development and integration to social environment. These interactions shape the teachers' professional conduct during all the stages of child' educational process.

Preoccupation of knowing teacher' professional conduct/ behaviour started with the Jensen in 1953 and today, the experts reveal the top 10 qualities of a great teacher. As the researches pointed, we can say that teacher's behaviour is beyond a simple indicator of the current teaching-learning act. It became more and more an expression of professional and personal brand.

In early education, teachers work side by side with child' parents, educational experts, counsellors in the best interest of the child for his/her suitable development and integration to social environment. These interactions shape the teachers' professional conduct during all the stages of child' educational process.

\section{Materials and Methods}

In this context, the following questions arise: which are the factors that affect the professional conduct of teachers involved in early education that have relevant impact upon child development? Are specific conditions that facilitate or not their professional conduct?

To answer this question, we developed an investigative research that had the aim to identify the elements that have impact upon professional conduct of teachers involved in early education and are relevant for quality of the early education; the wider goal was to see if teacher 'professional conduct can be predicted.

Our research focused on two major objectives: a) investigation the factors that affect the professional conduct at teachers involved in early education; b) investigation the conditions that facilitate/ or not the professional conduct of teachers involved in early education.

We started from the following hypothesis: taking into consideration that teachers involved in early education have sets of educational goals for their pupils, we will find specific manifestations of teachers' conduct in relation with their work' experience.

Participants.

Our research had an initial testing procedure on 15 Romanian teachers involved in early education and 15 Greek teachers involved in early education and the Cronbach Alpha index $(\alpha=.732)$ obtained allowed us to proceed to an extended psychological research. 
We performed our research on 37 Romanian teachers involved in early education, aged 28-54 years (with mean of 44.06 years and median $=40.05$ years), and on 37 Greek teachers involved in early education, aged 29-50 years (with mean of 43.08 years and median $=41.05$ years). The teacher' participation to this investigation was voluntary and based on personal accord. Distribution is uniform, skewness index values from .759 to 1.823 , and with a standard error of skewness from .642 to 1.577; kurtosis index values from .698 to 1.822, and with a standard error of kurtosis from .7115 to 1.639 .

The structure of the investigated teachers in relation with their work' experience is presented in figure no.1

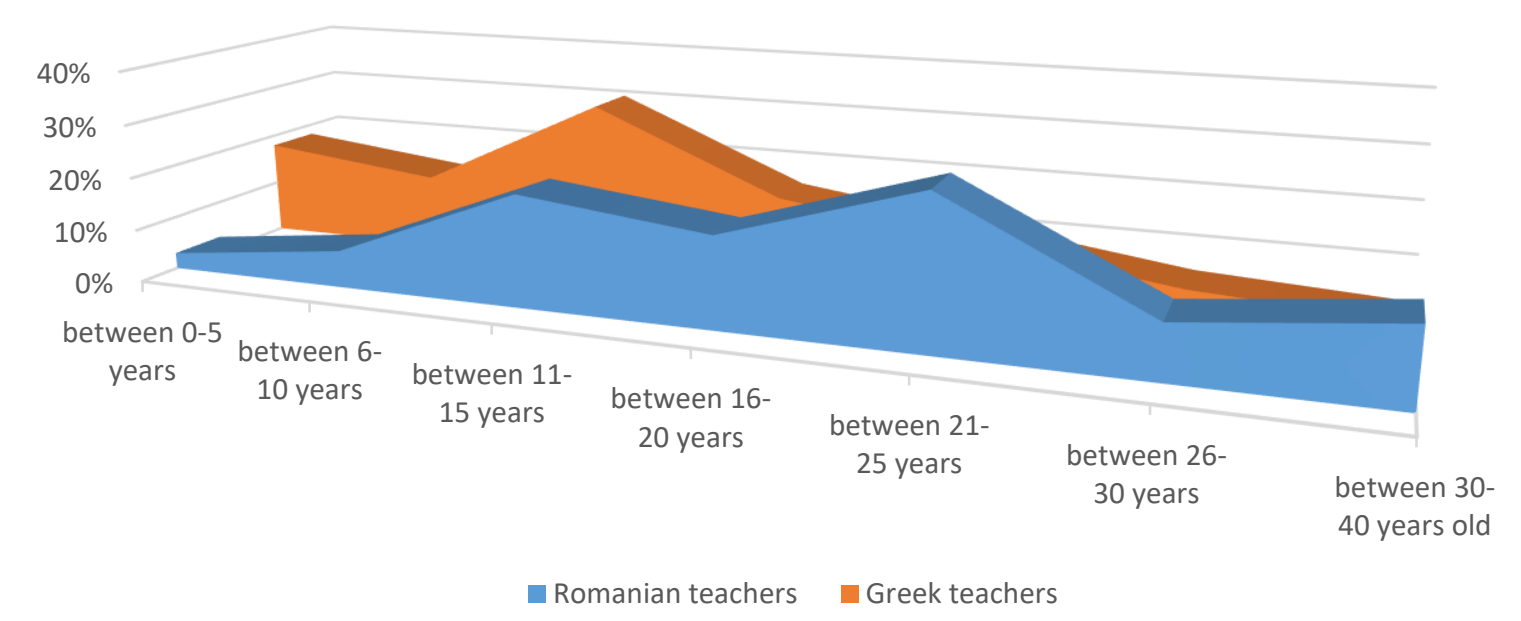

Figure 1: The distribution, by work' experience, of our investigated teachers

\section{Methods}

In our research we used the following instruments: a) the "Questionnaire for assessing teachers professional conduct" (Romanian version -internal consistency index $=.740$, fidelity index $=.724$; Greek version- internal consistency index $=.779$, fidelity index $=.742$, ); b) the "Questionnaire for assessing conditions of teachers quality services provided" (Romanian version -internal consistency index $=.759$, fidelity index $=.732$; Greek version- internal consistency index $=.795$, fidelity index $=.732$ ); c) non-directive interviews; d) statistical processing methods.

\section{Results and Discussions}

\subsection{Investigation of The Factors That Affect the Teachers' Professional Conduct}

Investigation of the factors that affect professional conduct was the object of concern of experts, in particular, coming from psychology, economy, sociology. The data collected from their researches proved to be valuable in order to understand organizations, to develop strategies that reduce the stress level among the employees, to improve the quality of the service provided, etc. There are a lot of researches done on dimension of teachers behaviour (Landy, F. J., \& LamiellLandy, 1978), on teachers 'decision process (Richard, Shavelson \& Stern,1981), on the teachers' perspectives on promoting learning (Blase, Blase,2000), on the influence of teacher' behavior on student's outcomes (Kyriakides, Creemers, \& Antoniou, 2009), etc. 
In this study, we were focus upon revealing the specific factors that affect the professional conduct of Romanian and Greek teachers involved in early education. Therefore, we used, in our assessment, a Lickert scale, with 5 levels of assessment; the data are presented in table no 1.

Table 1: Factors that have impact upon the professional conduct of investigated subjects

\begin{tabular}{|c|c|c|c|c|c|c|}
\hline \multirow[t]{2}{*}{ Factors } & \multirow{2}{*}{$\begin{array}{l}\text { Type of the } \\
\text { subjects }\end{array}$} & \multicolumn{5}{|c|}{ Levels of assessment (\%) } \\
\hline & & $\begin{array}{l}\text { Very } \\
\text { high }\end{array}$ & High & Medium & Low & $\begin{array}{l}\text { Very } \\
\text { low }\end{array}$ \\
\hline \multirow[t]{2}{*}{ Salary } & Romanian & 15.3 & 40.8 & 27.6 & 10.2 & 6.1 \\
\hline & Greek & 11 & 28.3 & 25.7 & 20 & 15 \\
\hline \multirow[t]{2}{*}{ Work 'schedule } & Romanian & 24 & 32 & 32 & 12 & 0 \\
\hline & Greek & 25 & 27.4 & 36.7 & 8.3 & 1.7 \\
\hline \multirow{2}{*}{$\begin{array}{l}\text { Creating teaching materials } \\
\text { tailored to each activity }\end{array}$} & Romanian & 44 & 42 & 14 & 0 & 0 \\
\hline & Greek & 43.3 & 41.7 & 11.7 & 1.7 & 1.7 \\
\hline \multirow{2}{*}{$\begin{array}{l}\text { Continuous improvement of } \\
\text { teaching / learning methods and } \\
\text { strategies for children }\end{array}$} & Romanian & 52 & 43.9 & 4.1 & 0 & 0 \\
\hline & Greek & 51.7 & 31.7 & 8.3 & 5 & 3.3 \\
\hline \multirow{2}{*}{$\begin{array}{l}\text { Continuous improvement of pre- } \\
\text { school child assessment methods } \\
\text { and strategies }\end{array}$} & Romanian & 44 & 46 & 10 & 0 & 0 \\
\hline & Greek & 35 & 31.7 & 21.7 & 8.3 & 3.3 \\
\hline \multirow[t]{2}{*}{ The constant pressure of parents } & Romanian & 26 & 18 & 36 & 14 & 6 \\
\hline & Greek & 18.3 & 16.7 & 31.7 & 11.7 & 21.7 \\
\hline \multirow{2}{*}{$\begin{array}{l}\text { Existing competition between } \\
\text { teachers at each kindergarten }\end{array}$} & Romanian & 18 & 28 & 38 & 14 & 2 \\
\hline & Greek & 16 & 29 & 23.8 & 13 & 18.1 \\
\hline \multirow{2}{*}{$\begin{array}{l}\text { Active participation in } \\
\text { extracurricular activities of } \\
\text { children }\end{array}$} & Romanian & 35.4 & 25 & 31.3 & 8.3 & 0 \\
\hline & Greek & 48.3 & 36.7 & 15 & 0 & 0 \\
\hline
\end{tabular}

The data presented in table no. 1 reflect, that the factor that has the highest impact, both on Romanian teachers and Greek teachers involved in early education is "continuous improvement of teaching / learning methods and strategies in preschools". The situation is not surprising, if we take in consideration that teachers are put in position of choosing and adapting (according with the current curricula validated by national authorities), the "wright contents" that will be used in education the little children. But, in order to choose and adapt the "wright contents" each teacher has to have in mind the methods and strategies that are suitable for using these contents.

Probably, these data will be better understood if are correlated with the data received from the impact of" creating teaching materials tailored to each activity". The interpretation of the correlated impact of those factors reveals that its act together in a systemic way (direct, significant correlation $\mathrm{r}=.723, \mathrm{p}=.05$ - at Romanian teachers, respectively direct, very significant correlation $\mathrm{r}=.836, \mathrm{p}=.05$ at Greek teachers) and become generic indicator in assessing the teacher "professional conduct that can be called "the efficacity of teaching act "; also reflect the vision in which pre-school children are educated: Romanian teachers develop materials according to the methods and strategies used to acquire the acquisitions stipulated in the national programs, and Greek teachers develop teaching materials and choose methods, strategies in order to meet children's needs. 
The analyses of the data collected, also show that for Romanian teachers the "continuous improvement of pre-school child assessment methods and strategies" has a higher impact. This situation can be explained easily if we take in consideration that evaluation (assessment) of activities together with teaching-learning activities are axes through which the process of education and modelling of preschool child is done.

The data collected from Greek teachers revealed also that they assessed "active participation in extracurricular activities of children "as having a high impact on their professional conduct, because, it seems that contributes decisively to creation of the institutional brand, to social valorisation of preschool children. This impact, in order to be understood properly, it has to be analysed in constant interaction with the "teaching materials tailored to each activity" (direct, significant correlation index $\mathrm{r}=.775, \mathrm{p}=.05$.). This interaction reveals that "active participation in extracurricular activities of children " is in fact the basic element that provides precious information on children's specificity features (personal values, interests, action limits, etc) in relation to which Greek teachers can create tailor-made teaching materials for each activity; and it became an index for assessing the Greek teachers' activities in term of efficacity.

The last but not least factor that has a high impact upon the teachers' professional conduct is "work schedule". It has been highlighted by both Romanian and Greek teachers and basically it is the direct consequence of the respect provided to teachers, of their "social status". But, when we analysed the answers came out from the non-directive in terms of personal significance of "work schedule", we found that the investigated teachers, who have an effective seniority in education between 21-25 years, appreciated the impact of "work "schedule" upon their professional conduct in relation with their personal satisfaction, while the teachers who have an effective seniority in education between the 11-15, appreciated the same impact in terms of professional affirmation, professional branding, and the efforts involved.

\subsection{Investigation Objectification Conditions of Teachers 'Professional Conduct}

The next aspect that we analysed in our investigation was to reveal that objectification conditions of the teachers' professional conduct. We used also a Lickert scale, with 5 levels of assessment; the data are presented in table no 2 . The collected data are in table no.2.

Table 2: Conditions that have impact upon teachers' professional conduct

\begin{tabular}{|l|l|l|l|l|l|l|}
\hline \multirow{1}{*}{ Conditions analysed } & \multirow{2}{*}{$\begin{array}{c}\text { Type of the } \\
\text { subjects }\end{array}$} & \multicolumn{5}{c|}{ Levels of assessment (\%) } \\
\cline { 3 - 8 } & & $\begin{array}{c}\text { Very } \\
\text { high }\end{array}$ & High & Medium & Low & $\begin{array}{c}\text { Very } \\
\text { low }\end{array}$ \\
\hline \multirow{2}{*}{$\begin{array}{l}\text { The teacher' reputation among } \\
\text { child' parents }\end{array}$} & Romanian & 54 & 45 & 1 & 0 & 0 \\
\cline { 2 - 8 } & Greek & 18.3 & 34.3 & 35 & 7.3 & 5 \\
\hline $\begin{array}{l}\text { Good relations in the classroom } \\
\text { with children }\end{array}$ & Romanian & 84 & 16 & 0 & 0 & 0 \\
\cline { 2 - 8 } & Greek & 61 & 35.2 & 3.5 & 0 & 0 \\
\hline \multirow{2}{*}{$\begin{array}{l}\text { Approaching child as partner of } \\
\text { learning process }\end{array}$} & Romanian & 82 & 18 & 0 & 0 & 0 \\
\cline { 2 - 8 } & Greek & 57.5 & 37.3 & 3.1 & 0 & 0 \\
\hline Assessment tools & Romanian & 77 & 18 & 5 & 0 & 0 \\
\cline { 2 - 8 } & Greek & 46.4 & 38.7 & 13.1 & 1.9 & 0 \\
\hline & Romanian & 67 & 34 & 1 & 0 & 0 \\
\hline
\end{tabular}




\begin{tabular}{|l|l|l|l|l|l|l|}
\hline $\begin{array}{l}\text { Training courses/sessions of } \\
\text { professional and personal } \\
\text { development }\end{array}$ & Greek & 73.8 & 23.1 & 3 & 0 & 0 \\
\hline $\begin{array}{l}\text { Exchanges in good practices with } \\
\text { other colleagues }\end{array}$ & Romanian & 75 & 19 & 6 & 0 & 0 \\
\cline { 2 - 8 } & Greek & 22 & 21.7 & 35.7 & 14 & 6.7 \\
\hline System of educational policies & Romanian & 77 & 11 & 2 & 0 & 0 \\
\cline { 2 - 8 } & Greek & 20 & 21.8 & 36.6 & 14 & 7.7 \\
\hline
\end{tabular}

From the data presented in table no 2, we can notice that the Romanian teachers involved in early education revealed "good relations in the classroom with children" as the most conditional element of their professional conduct. What means this thing?

For a better understanding of these data, we conducted non-directive 35 interviews and we could see that revealed "good relations in the classroom with children" were associated by our investigated Romanian teachers with the well-being of the children they educated and by that, with the necessity of ensuring a safe educational environment for all the children. So, it seems that ensuring a safe educational environment (which implies respect for the children' resourceselement of deontological code) determines a constant modelling process of teachers' professional conduct.

On second place, the Romanian teachers involved in early education, pointed as conditional element with high relevance upon the teacher's professional conduct: "approaching child as partner of learning process". This assessment is not surprising, if it is correlate with the first one. Together, those two elements that influence the Romanian teachers' professional conduct, are the bases of an efficient educational act and become quality assessment indicators for educational services addressed to small children.

Instead, the Greek teachers involved in early education pointed "training courses/sessions of professional and personal development" as having the greatest relevance of objectivation of their professional conduct and highlights the constant need of these teachers to update their knowledge, skills, abilities in order to provide best educational services in the context of respecting children's rights, ethnicity.

In the second place, the investigated Greek teachers, pointed as the next element that is relevant for objectivation of their professional conduct: "good relations in the classroom with the children". For Greek teachers, this element which conditions professional conduct, has a greater significance if we take into consideration the cultural diversity of the children to whom it offers educational services and can be considered as an indicator of the quality of the integrated educational services provided for little children in kindergartens.

The rest of the elements that objectify the teachers' professional conduct (Romanian and Greek teachers) contribute teachers' professional branding objectification process in relation with the local and regional resources. 
The statistical correlational data pointed the existence of significant correlations, at teachers involved in early education, between the factors that influence their professional conduct and the objectification conditions:

\section{Romanian Teachers}

"continuous improvement of pre-school child teaching/ learning methods and strategies" and "good relations in the classroom with children" and "(direct, highly significant correlation $\mathrm{r}=$. $875, \mathrm{p}=.05)$

"continuous improvement of pre-school child assessment methods and strategies" and "approaching child as partner of learning process" (direct, highly significant correlation $\mathrm{r}=.898$, $\mathrm{p}=.01)$

"work schedule" and "good relations in the classroom with the children" "(direct, highly significant correlation $\mathrm{r}=.827, \mathrm{p}=.05$ )

\section{Greek Teachers}

"active participation in extracurricular activities of children" and "training courses/sessions of professional and personal development (direct, highly significant correlation $\mathrm{r}=.852, \mathrm{p}=.01$ ).

"work schedule" and "good relations in the classroom with the children" "(direct, highly significant correlation $\mathrm{r}=.838, \mathrm{p}=.05$ )

\section{Conclusions and Recommendations}

This research had the goal to reveal the elements that have impact upon professional conduct of teachers involved in early education and are relevant for quality of the early education.

We used in our investigation Romanian version and Greek version of the specific questionnaires. We found that:

1) factors affect the teachers' professional conduct more or less in relation with the associated values to attributed significance attributed.

2) the conditions that objectified the teachers' professional conduct didactic behaviour of the investigated teachers is the consequence of the teachers' professional brand and produces differentiating medium- and long-term effects on the personality of the pre-schoolers.

The assumption of our research was confirmed.

We can use the previous conclusions for:

- developing professional training sessions for using new, modern strategies at preschool children;

- developing assessment' methods addressed to preschool children;

- encouraging the "good practices changes" between teachers that work with little children;

- developing stress copying techniques for teachers that work with little children. 


\section{References}

[1] Blase,J., Blase,Jo (2000). Effective instructional leadership: Teachers' perspectives on how principals promote teaching and learning in schools", Journal of Educational Administration, 38 (2), 130-141.

[2] Frankel, M. S. (1989). Professional Codes: Why, How and With What Impact? Journal of Business Ethics. 8: 109-115. 1989.

[3] Fugărețu-Urea, R. (2007). Introducere în psihopedagogia devianţei şi inadaptării comportamentale. Bucureşti: Editura Fundaţiei România de Mâine.

[4] Jensen, A. (1953). Definition of Teacher Behavior Encompasses Many Traits. Educational Horizons. vol. 32, No. 2, TEACHERS FOR 1960? (WINTER, 1953), 125-128,

[5] Kyriakides, L, Creemers, B.P.M., Antoniou, P (2009). Teacher behaviour and student outcomes: Suggestions for research on teacher training and professional development. Teaching and Teacher Education Journal 25 (2009) 12-23.

[6] Landy, F. J., Lamiell-Landy, A. (1978). Dimensions of teacher behavior. Journal of Applied Psychology, 63(4), 522-526.

[7] Martin, W. (2013). Beyond the Hippocratic Oath: Developing Codes of Conduct in Healthcare Organizations. OD Practitioner, 45(2), 26-30.

[8] Michael, D., Stark., A. (2001). Conflict of Interest in the Professions. Vol. VI The Oxford Series. Oxford University Press.

[9] Payne, D., Landry, B. J. L. (2006). A uniform code of ethics: business and it professional ethics. Communications of the ACM, 49(11), 81-84

[10] Radu I. \&all (1991). Introducere în psihologia contemporană. Cluj Napoca: Editura Sincron.

[11] Richard, J., Shavelson, R.J., Stern, P. (1981). Research on Teachers' Pedagogical Thoughts, Judgments, Decisions, and Behavior, Review of Educational Research 51 (4) 455-498.

[12] Sommer, M. J. (2001). Ethical Codes of Conduct and Organizational Context: A Study of the Relationship Between Codes of Conduct, Employee Behaviour and Organizational Rules", Journal of Business Ethics, 30: (2001) 185-195.

[13] Șchiopu U. (coord.) (1995). Dicţionar de psihologie. București: Editura Babel

[14] ***Top 10 Qualities of a Great Teacher, available on http://teaching.org/resources/top-10qualities-of-a-great-teacher, access on 10.03.2019

[15] Weinberg, M., \& Campbell, C. (2014). From Codes to Contextual Collaborations: Shifting the Thinking About Ethics in Social Work. Journal of Progressive Human Services, 25(1), 37-49. doi: $10.1080 / 10428232.2014 .856739$

*Corresponding author.

E-mail address: roxana.urea@fpse.unibuc.ro 